\title{
Accelerated Executive Review
}

National Cancer Institute

\section{Source}

National Cancer Institute. Accelerated Executive Review. NCI Thesaurus. Code C19962.

Mechanism to fund single project applications in patient oriented or basic research near

the payline and for which reviewer criticisms can be addressed quickly. (Bypass Budget) 